REVista del Posgrado EN DEREcho de la unAM

NuEVA ÉPOCA, AÑo 4, NúM. 7, JuLiO - Diciembre 2017

\title{
LA ALIENACIÓN PARENTAL Y SU REGULACIÓN EN MÉXICO, UNA OMISIÓN EN SU LEGISLACIÓN
}

PARENTAL ALIENATION AND ITS REGULATION IN MEXICO, AN OMISSION IN ITS LEGISLATION

\author{
Adolfo EduARdo Cuitláhuac Montoya López ${ }^{1}$ \\ Y JAQUELINE RIVAS DUARTE ${ }^{2}$
}

RESUMEN: El presente artículo examina si la falta de reconocimiento científico de la alienación parental como un síndrome o en su caso un exceso en su sanción, es o no, motivo suficiente para omitir su regulación en la legislación nacional; o bien, si la alienación parental existe como una conducta actual, misma que puede ser corroborada mediante dictámenes psicológicos u otros métodos, y por tanto, existe la necesidad de su regulación.

Igualmente, el presente analiza la decisión tomada por la Asamblea Legislativa del Distrito Federal, al derogar el artículo 323 Séptimus del Código Civil del Distrito Federal, que regulaba y sancionaba la alienación parental, y si ésta constituye o no, una omisión legislativa en perjuicio de los derechos de las niñas, niños y adolescentes; contrastada con los criterios establecidos por la Suprema Corte de Justicia de la Nación en la acción de inconstitucionalidad número 11/2016, resuelta el 24 de octubre de 2017.

Finalmente, propone un análisis respecto de la imposición de medidas o sanciones, a todas aquellas personas que incurran en conductas de alienación parental, pues como ya se dijo, la propia Suprema Corte de Justicia de la Nación, ya ha declarado inconstitucional que la consecuencia de la alienación parental sea la suspensión o pérdida de la patria potestad de los padres sobre el menor.

PAlABRAs ClAve: Alienación parental; SAP; síndrome; familia; hijos; menores; Código Civil; medidas; padre, madre; patria potestad; síndrome, guarda; custodia; discriminación; maltrato; omisión.

\footnotetext{
${ }^{1}$ Profesor de Tiempo completo titular "B”, en la Universidad Nacional Autónoma de México, candidato al Sistema Nacional de Investigadores.

${ }^{2}$ Licenciada en Derecho egresada de la Facultad de Derecho de la Universidad Nacional Autónoma de México (UNAM), realizó estudios de Posgrado en "Negociación y Gestión de Conflictos Políticos y Sociales” en la Facultad de Ciencias Políticas y Sociales de la UNAM.
} 
ABstract: The present article examines whether the lack of scientific recognition of parental alienation as a syndrome or in its case as an excess in its usage, it is or is not enough reason to leave aside its regulation in the national legislation; or, if the parental alienation exists as a current behavior, which can be corroborated by psychological opinions or other methods, and therefore, there is a need for its regulation.

Also, this document analyzes the decision taken by the Legislative Assembly of the Federal District, by repealing article 323 Septimus of the Civil Code of the Federal District, which regulated and sanctioned parental alienation, and if it constitutes or not, a legislative omission that undermines the rights of children and adolescents; contrasted with the criteria established by the Supreme Court of Justice of the Nation in the action of unconstitutionality number 11/2016, resolved on October 24, 2017.

Finally, it proposes an analysis regarding the imposition of measures or sanctions, to all those persons who engage in behaviors of parental alienation, because as above mentioned, the Supreme Court of Justice of the Nation, has already declared unconstitutional that the consequence of parental alienation is the suspension or loss of parental rights of the parents over the child.

KEYWORDS: Parental alienation; PAS; syndrome; family; children; minors; Civil Code; measures; father, mother; parental rights; syndrome, guardianship; custody; discrimination; abuse; omission.

SumARIO: I. Introducción; II. Conceptos Preliminares sobre Alienación Parental; III. Decreto por el que se deroga el artículo 323 Séptimus del Código Civil del Distrito Federal y la Acción de Inconstitucionalidad 11/2016; IV. Trato Legislativo; V. Clasificación de las omisiones legislativas. VI. Propuesta para una efectiva regulación de la alienación parental; VII. Fuentes.

\section{INTRODUCCIÓN}

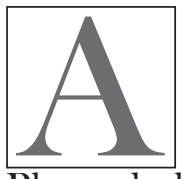

ctualmente en nuestro país, se mantiene la necesidad de continuar con el análisis de la alienación parental, ya que aún y cuando el 24 de octubre de 2017, el Tribunal en Pleno de la Suprema Corte de Justicia de la Nación por mayoría de nueve votos, determinó validar la constitucionalidad de la figura de “alienación parental” como un fenómeno existente y diagnosticable, esto no ha resuelto completamente el tema de raíz, ya que actual- 
mente sigue existiendo disparidad de criterios legislativos en todo el país, así como un número considerable de Asociaciones Civiles en defensa de los derechos de los niños y las mujeres, que reprueban la aceptación del síndrome de alienación, pues advierten que su configuración impide detectar casos de abuso y violencia en contra de los menores; así mismo, consideran que dicha figura, fomenta la discriminación y crea estereotipos basados en el género, que afectan particularmente a las mujeres.

Por otra parte, no puede pasarse por alto que la práctica judicial ha demostrado que la manipulación parental existe y se presenta frecuentemente, dentro de los juicios del orden familiar, produciendo efectos negativos en la psique del menor que es objeto de dicha manipulación, por lo que no es posible pasar por alto dicha situación, y es necesario en su caso, su regulación.

Así las cosas, la cuestión es determinar si para su regulación es necesario que esta conducta sea aceptada por la comunidad científica como un "síndrome" o no, pues de no ser así, nada impide que sea considerada en todas las legislaciones locales del país como un fenómeno social, el cual requiere ser regulado, tal como lo estableció la Suprema Corte de Justicia de la Nación al resolver la acción de inconstitucionalidad 11/2016.

En tal tenor, debe establecerse un criterio sobre la imposición de medidas o sanciones, a todas aquellas personas que lleven a cabo conductas de alienación parental, pues como ya se verá, nuestro máximo Tribunal, ha declarado inconstitucional que la consecuencia de la alienación parental sea la suspensión o pérdida de la patria potestad de los padres sobre el menor.

\section{CONCEPTOS PRELIMINARES SOBRE ALIENACIÓN PARENTAL}

\section{ANTECEDENTES DEL SÍNDROME DE ALIENACIÓN PARENTAL}

De acuerdo con lo expuesto por el Psicólogo José Manuel Aguilar, en su libro intitulado "Síndrome de Alienación Parental", el primer autor que definió el Síndrome de Alienación Parental (SAP) fue Ri- 
chard Gardner(1985), en un artículo intitulado "Tendencias recientes en el divorcio y la litigación por la custodia.” De igual forma, en la segunda edición de su libro "El Síndrome de Alienación Parental”, definió al Síndrome de Alienación Parental como:

Un trastorno que surge principalmente en el contexto de las disputas por la guarda y custodia de los niños. Su primera manifestación es una campaña de difamación contra uno de los padres por parte del hijo, campaña que no tiene justificación. El fenómeno resulta de la combinación del sistemático adoctrinamiento (lavado de cerebro) de uno de los padres y de las propias contribuciones del niño dirigidas a la denigración del progenitor objeto de esta campaña. ${ }^{4}$

En esa misma línea, al realizar un análisis de la teoría propuesta por Gardner, el autor José Manuel Aguilar, finalmente concluyó con la siguiente definición:

El Síndrome de Alienación Parental (SAP) es un trastorno caracterizado por el conjunto de síntomas que resultan del proceso por el cual un progenitor transforma la conciencia de sus hijos, mediante distintas estrategias, con objeto de impedir, obstaculizar o destruir sus vínculos con el otro progenitor, hasta hacerla contradictoria con lo que debería esperarse de su condición. ${ }^{5}$

De ambas definiciones, sobresalen tres elementos fundamentales que lo constituyen: Primero se trata de una "campaña de difamación, desprestigio o manipulación” en contra de uno de los padres; segundo, no existe justificación que avale dicha campaña; y tercero, se deriva de un sistemático adoctrinamiento por parte del padre alienador, en donde incluye la contribución del niño o adolescente a esta campaña; tomando como eje principal, no sólo la manipulación o "lavado de cerebro" que sufre el niño (quien es la víctima principal),

\footnotetext{
${ }^{3}$ Richard Gardner fue profesor de Psiquiatría Clínica en el Departamento de Psiquiatría Infantil de la Universidad de Columbia, en los Estados Unidos de Norteamérica.

${ }^{4}$ Aguilar, José Manuel, Síndrome de Alienación Parental, 5ª Ed., Madrid, Almuzara, S.L., 2006, p. 27.

${ }^{5}$ Ibíd., p. 29.
} 
sino poniendo como un elemento sumamente importante, al progenitor alienado, quien a decir del concepto establecido por Gardner, resulta víctima del propio menor alienado.

Por su parte, el autor Iñaki Bolaños, al citar a Richard Gardner explica que la manifestación primaria del SAP, se desarrolla de la siguiente manera:

[...] es la campaña de denigración de un hijo hacia uno de sus progenitores, una campaña que no tiene justificación. El hijo está esencialmente preocupado por ver a un padre como totalmente bueno y al otro como lo contrario. El "padre malo" es odiado y difamado verbalmente mientras que el "padre bueno" es amado e idealizado. Según este autor, es el resultado de una combinación entre los adoctrinamientos de un padre "programador" y las propias contribuciones del niño, para vilipendiar al padre "diana”. En los casos en que ha evidencia de abuso o negligencia, la animadversión del niño está justificada y, por tanto, la explicación de su hostilidad mediante este síndrome no es aplicable. ${ }^{6}$

Asimismo, la Psicóloga Asunción Tejedor Huerta, en su libro El Síndrome de Alienación Parental. Descripción y Abordajes Psico-Legales, resalta los siguientes aspectos sobre el SAP:

[...]“...la acción consciente de uno de los padres en contra de otro para que pierda el afecto, el amor, el respeto y la consideración de sus hijos” (Dr. Lowenstein).

De esta forma, preocupado por el número cada vez mayor de niños que durante las evaluaciones para la custodia iniciaban un proceso de denigración hacia uno de los progenitores, llegando incluso a expresar odio, Gardner comenzó a estudiar estos síntomas en los niños y utilizó el término de "Síndrome de Alienación Parental" para referirse a los síntomas que se veían en los niños después de

${ }^{6}$ Bolaños, Iñaki, "El Síndrome de Alienación Parental. Descripción y Abordajes Psico-Legales”, Psicopatología Clínica, Legal y Forense, [en línea], Madrid, Vol. 2, No. 3, 2002, p. 28. [fecha de consulta: 27 de febrero de 2018], Disponible en:

<http://eoepsabi.educa.aragon.es/descargas/G_Recursos_orientacion/g_4_orientacion_familiar/g_4.3.separacion/2.5.SAP_abordaje_psico-legal.pdf>. 
una separación o divorcio, tales como la denigración y el rechazo de un padre, el cual antes era amado.

Paralelamente a esta posición, dos psicólogos americanos, Blush y Ross (1987), utilizaron el término SAID "Sexual Allegations In Divorce" (Acusaciones de Abusos Sexuales en el Divorcio), en donde presentaban tipologías del padre que acusaba en falso, del niño involucrado y del padre acusado, y donde se mencionaba la rabia que podía estar presente en estos procesos y la patología del padre alienador. ${ }^{7}$

Igualmente la psicóloga Asunción Tejedor Huerta, al abundar en el tema, resalta un elemento fundamental, "la acción consciente" del progenitor alienador, de manipular y colocar a los hijos en un estado hostil en contra del progenitor alienado, por lo que se deduce que al no contar con la intención, no podría hablarse de una conducta de alienación parental; lo que hace aún más complicado determinar si un menor sufrió de alienación parental por parte de alguno de sus padres, pues tendría que probarse la intención de manipularlo. ${ }^{8}$

Por otra parte, el autor Iñaki Bolaños, al evaluar los síntomas propuestos por Richard Gardner para detectar la alienación parental, concluyó lo siguiente:

Gardner describe una serie de "síntomas primarios", mismos que usualmente aparecen juntos en los niños afectados por el "SAP":

1. Campaña de denigración. El niño está obsesionado con odiar a uno de los progenitores. Esta denigración a menudo tiene la cualidad de una especie de "letanía".

2. Débiles, absurdas o frívolas justificaciones para el desprecio. El niño plantea argumentos irracionales y a menudo ridículos para no querer estar cerca de su padre.

3. Ausencia de ambivalencia. Todas las relaciones humanas, incluidas las paterno-filiales, tienen algún grado de ambivalencia. En

\footnotetext{
${ }^{7}$ Tejedor Huerta, Asunción, El Síndrome de Alienación Parental, Una forma de maltrato, Madrid, EOS, 2006, EOS Psicología Jurídica, p. 19.

${ }^{8}$ Cfr., Tejedor Huerta, Asunción, op. cit.
} 
este caso, los niños no muestran sentimientos encontrados. Todo es bueno en un padre y todo es malo en el otro.

4. Fenómeno del "pensador independiente". Muchos niños afirman orgullosamente que su decisión de rechazar a uno de sus progenitores es completamente suya. Niegan cualquier tipo de influencia por parte del padre aceptado.

5. Apoyo reflexivo al progenitor "alienante" en el conflicto parental. Habitualmente los niños aceptan incondicionalmente la validez de las alegaciones del padre aceptado contra el odiado, incluso cuando se les ofrece evidencia de que aquél miente.

6. Ausencia de culpa hacia la crueldad y la explotación del progenitor "alienado". Muestran total indiferencia por los sentimientos del padre odiado.

7. Presencia de argumentos prestados. La calidad de los argumentos parece ensayada. A menudo usan palabras o frases que no forman parte del lenguaje de los niños.

8. Extensión de la animadversión a la familia extensa y red social del progenitor "alienado". El niño rechaza a personas que previamente suponían para él una fuente de gratificaciones psicológicas. ${ }^{9}$

[...] Aunque las descripciones de Gardner sobre el síndrome dibujan con nitidez un auténtico problema familiar y legal, sus conceptualizaciones teóricas sobre la causalidad del "SAP" y las repercusiones en su "tratamiento" son susceptibles de algunos cuestionamientos.

Parece arriesgada la pretensión del autor de que su teoría sea utilizada legalmente como base para decisiones judiciales de cambio de custodia, de penalizaciones al progenitor "alienante" o de consideraciones sobre la falsedad de algunas alegaciones de abuso sexual o maltrato en el contexto de las disputas de separación y divorcio. Es obvio que el problema existe, pero una atribución causal tan subjetiva puede generar decisiones judiciales con peligrosas repercusiones para los hijos. ${ }^{10}$

De este modo, es claro que para el autor, a pesar de que acepta la existencia de un problema familiar que tiene repercusiones en el

\footnotetext{
${ }^{9}$ Bolaños, Iñaki, op. cit., nota 3, p. 29.

${ }^{10}$ Ibíd., p. 40.
} 
ámbito legal, no acepta la forma en que el psiquiatra Gardner pretende dar tratamiento a dicha figura, así como tampoco acepta el impacto legal que puedan otorgarle a dicho "síndrome" los juzgadores a la hora de realizar sus determinaciones, mismos que pueden llegar incluso a la perdida de la patria potestad del progenitor que incurra en dicha figura.

Al igual que Bolaños, quien no es un opositor de Gardner, sino que únicamente critica su postura subjetiva y los alcances de su teoría; también existen personalidades que han decidido cuestionar su teoría al aseguran que no se trata de un síndrome, y que éste ha sido utilizado para manipular el sistema judicial, así como el sentido de las resoluciones en casos donde se define la guarda y custodia de los menores; en esa línea, se posicionan las autoras Consuelo Barea Payueta y Sonia Vaccaro en su libro intitulado El Pretendido Síndrome de Alienación Parental, un Instrumento que Perpetúa el Maltrato y la Violencia, hacen referencia al caso Grieco Vs. Sccott, llevado a cabo en una corte de Estados Unidos, siendo éste, el primer caso en donde participó el psiquiatra Richard Gardner y utilizó el término "Síndrome de Alienación Parental”; según lo señalado por estas autoras al mencionar que:

En el año 1985, Richard A. Gardner, nombra por primera vez este "síndrome", y lo posiciona en el litigio entre cónyuges, en el marco de un divorcio y por la tenencia de los hijos.

Dos años más tarde, en 1987, Gardner publicó a través de su propia editorial: Creative Therapeutics, El Síndrome de Alienación Parental y la diferencia entre abuso sexual infantil fabricado y genuino, ubicando a este supuesto síndrome en la justicia y el marco del litigio por divorcio. Luego hace mención a las denuncias -siempre en el ámbito judicial - de acusaciones de incesto hacia uno de los progenitores, diciendo que casi siempre la denunciante es la madre, y quien es denunciado/acusado, es el padre. Señalando que la mayoría de estas denuncias serían falsas.

En noviembre de 1989, en un ejemplar de la revista "American Fatherhood, The voice of Responsible and Dedicated Fatherhood F.A.I.R. The National Fathers' Organization”, de la Organización Nacional de 
Padres - de la ciudad de Camden, Delawere, aparece publicado un artículo firmado por Richard Gardner: "Parental Alienation Syndrome", en cuyo subtítulo interroga. ¿Por qué algunas madres ejercen todo su poder para expropiar al niño del padre?, ¿Qué hacerse?

Con el paso del tiempo, Richard Gardner, logra posicionar este "síndrome" en la justicia, en los litigios de divorcio donde se debatía la tenencia de los hijos y en contra de las madres, y de modo muy especial, cuando surgía una a casación por incesto.

De este modo, el "SAP", no sólo otorgaba un argumento ad hoc para la defensa en este tipo de casos, sino que instalaba la sospecha sobre la víctima: los niños y las niñas. Peligrosamente en los casos de incesto, devaluando la palabra y creando la sospecha sobre el testimonio infantil, cuando en la casi totalidad de los abusos sexuales en la infancia, la palabra de los niños es la única prueba para iniciar una investigación.

A través de su utilización, exclusivamente en el ámbito judicial, este pretendido síndrome, se fue instalando, en especial entre psicólogos/ as, abogados/as, peritos y funcionarios/as de justicia. Su utilización se multiplicó exponencialmente y al día de hoy, en algunos países, sigue instalado en el desconocimiento de muchos profesionales que, no obstante, lo utilizan como elemento diagnóstico. ${ }^{11}$

Como puede observarse, la posición adoptada por las autoras Consuelo Barea y Sonia Vaccaro, acerca de los estudios y la metodología empleada por el Psiquiatra Richard Gardner, para considerar a la Alienación Parental como un síndrome, son poco confiables, y a decir de dichas autoras, no cumple con las características necesarias para ser considerado un síndrome, por tanto, se trata de un concepto sin fundamento médico-psiquiátrico, utilizado por quienes participan en la administración de justicia y por los litigantes, para robustecer sus argumentos y obtener una resolución favorable para sus clientes, en su mayoría varones.

${ }^{11}$ Vaccaro, Sonia y Barea, Consuelo, El Pretendido Síndrome de Alienación Parental, un Instrumento que Perpetúa el Maltrato y la Violencia, Bilbao, Desclée De Brouwer, S.A., 2009, pp. 48-50. 
Así las cosas, es vital para la comprensión del presente trabajo integrar la definición de la palabra "síndrome", ya que sin la misma, será imposible diferenciar entre las características que propone Richard Gardner para el diagnóstico de la alienación parental, y las características propias de un fenómeno social, que si bien no constituye un trastorno mental, es una conducta que debe ser regulada.

Sobre este tema, el autor Stanley Jablonski, realizó un análisis etimológico e histórico de la palabra síndrome, donde estableció algunos de los acontecimientos más importantes, que han rodeado el uso de este término.

[...] El término síndrome (de la palabra griega syndrome "simultaneidad”) se definió tradicionalmente como un estado patológico asociado a una serie de síntomas simultáneos, generalmente tres o más. La utilización de la palabra solía tener un carácter provisional, con la esperanza de que una vez confirmado ese estado, se remplazaría por un término más preciso. Es una de las palabras más antiguas que con mayor frecuencia se ha utilizado y mal empleado en el vocabulario médico moderno. El significado de síndrome siguió siendo en gran medida el mismo desde los tiempos de Hipócrates hasta bien avanzado el siglo XVII, cuando Thomas Sydenham llegó a la conclusión de que síndrome y enfermedad eran sinónimos, y la primera de estas palabras desapareció virtualmente de la literatura durante casi dos siglos por considerarse una denominación superflua. A finales del siglo XIX se produjo un redescubrimiento del término, al comprobarse que los métodos existentes para designar los estados patológicos mediante la combinación de los nombres de los órganos afectados con prefijos y sufijos apropia dos resultaban inadecuados para enfrentar trastornos complejos como anomalías múltiples, problemas con el metabolismo y trastornos que abarcan a varios sistemas u órganos. Muchos síndromes recibieron denominaciones epónimas, fundamentalmente porque su complejidad no admitía nomenclaturas descriptivas simples y, en parte, para procurar otorgar el reconocimiento adecuado a aquellos que fueron los primeros en descubrirlos. [...]

Ampliar el significado de la palabra síndrome fue otra de las etapas de la evolución del término que tuvo una influencia muy profunda en la 
manera en que ahora se utiliza. Su definición originalmente estrecha (estado caracterizado por un conjunto específico de síntomas) se amplió para designar las complejidades especiales y, en ocasiones, indefinidas (¿características del síndrome?) de enfermedades ya designadas, donde casos muy conocidos, como la malaria y la tuberculosis, pasaron a ser el síndrome de la malaria y el síndrome de la tuberculosis, respectivamente. Esta práctica, que en sus inicios se observó fundamentalmente en la literatura rusa de la posguerra, se llegó a utilizar gradualmente en la mayoría de las publicaciones médicas a escala mundial. En una ulterior ampliación del alcance del término, síndrome se suele utilizar ahora como sinónimo de una amplia diversidad de términos, entre los que se incluyen enfermedad, complejo de síntomas, signo, manifestación y asociación.

Cuando se utiliza solamente para denotar cuadros clínicos específicos, el término síndrome también se aplica con frecuencia como concepto para describir grupos de enfermedades similares o conexas; por ejemplo, el síndrome mielodisplástico representa una clase amplia de citopenias, y el síndrome del dolor de cabeza no es un síndrome en el sentido tradicional, sino más bien un conjunto amplio de enfermedades neurológicas que incluyen la cabeza, el cuello y la garganta que tienen, en otro respecto, poco en común. En definitiva, síndrome, de su función tradicional como término exclusivamente médico, se convirtió en una palabra para todo uso que denota todo aquello que sea extraño, fuera de lo común, o humorístico ya sea desde el punto de vista médico, de la conducta, social o cultural. En su uso actual, el término se asemeja mucho a Proteo, dios de la mitología griega que poseía el don de tomar varias formas, y, por tanto, es indefinido, probablemente indefinible, porque presenta un rostro diferente cuando lo enfrentamos y porque significa lo que se desee que signifique.

No existe una definición única que refleje adecuadamente todas las variantes de uso del término síndrome. Una de las acepciones aplicadas generalmente por los dismorfólogos y genetistas, quienes son los principales usuarios del término, lo describe como un "cuadro clínico etiológicamente definido de patogénesis desconocida que no debe confundirse con el 'complejo de síntomas de una enfermedad', o 'secuencia', que se refiere solamente a aquellas afecciones caracterizadas por conjuntos de síntomas similares o idénticos”. 
En otras esferas, el término se utiliza de manera diferente y su definición y alcance se están adaptando a las necesidades de cada autor. ${ }^{12}$

De esta explicación podemos concluir que, la palabra síndrome se suele utilizar como sinónimo de una diversidad de términos, entre los que se incluyen enfermedades, síntomas, indicadores, patologías, etc., que van ampliamente ligados a cuestiones de salud física o mental. Por lo cual, la alienación parental como una conducta o fenómeno social, consiste en un proceso a través del cual el progenitor alienador, utilizan tácticas o estrategias para manipular la voluntad de los hijos, con el fin de terminar con los vínculos emocionales que existen entre los hijos y el progenitor alienado; siendo el caso particular, que a simple vista, no cumple con las características propias de una enfermedad o patología; sin embargo, esta cuestión no corresponde determinarla a la ciencia jurídica, sino a otras disciplinas como la medicina, psiquiatría o la psicología.

Igualmente, no debemos pasar por alto, que uno de los objetivos del Derecho es la regulación de la conducta humana en la sociedad, así como el establecimiento de normas en los procesos legislativos, que protejan a los sectores sociales con mayor desventaja frente a los otros, por lo cual, es obligación del Estado el legislar conductas que afecten a los niños, niñas y adolescentes, como es caso de la alienación parental.

Tal como se explicó, en el año de 1985, Richard Gardner inicio su investigación sobre este tema otorgando una definición concreta a esta conducta, siendo su intervención, el inicio de diversos estudios formales del mismo. Sin embargo, en nuestro país aún en dicho año, se seguía ignorando sobre este nuevo concepto, pues únicamente se daba tratamiento y atención a los casos de violencia familiar de forma genérica; fue hasta el año 2011, que comenzó a legislarse sobre la alienación parental en los códigos civiles y familiares de al-

\footnotetext{
${ }^{12}$ Stanley, Jablonski, Síndrome: un concepto en evolución. ACIMED [en línea]. 1995, vol.3, n.1, pp. 30-38. ISSN 1024-9435, [fecha de consulta: 27 de febrero de 2018], disponible en: <http://scielo.sld.cu/scielo.php?script=sci_arttext\&pid=S1024-94351995000100006>.
} 
gunas Entidades Federativas; tal son los casos de Aguascalientes ${ }^{13}$, Baja California Sur ${ }^{14}$, Colima $^{15}$, Durango ${ }^{16}$, Guanajuato ${ }^{17}$, Jalisco $^{18}$, Michoacán ${ }^{19}$, Morelos $^{20}$, Nayarit ${ }^{21}$, Nuevo León ${ }^{22}$, Querétaro ${ }^{23}$, Ta-

${ }^{13}$ Véase el Artículo 434, párrafo segundo, del Código Civil del Estado de Aguascalientes, publicado en el Suplemento al No. 49 del Periódico Oficial del Estado de Aguascalientes, el 7 de diciembre de 1947, última reforma publicada en el Periódico Oficial el 28 de diciembre de 2015.

${ }^{14}$ Véase el Artículo 323 Bis, del Código Civil para el Estado Libre y Soberano de Baja California Sur, publicado en el Boletín Oficial del Gobierno del Estado de Baja California Sur el 19 de Julio de 1996, última reforma publicada BOGE 31-12-2017

${ }^{15}$ Véase el Artículo 411, párrafo tercero, del Código Civil para el Estado de Colima, publicado en el Suplemento del Periódico Oficial "El Estado de Colima", el 25 de Septiembre de 1954, última reforma Decreto 154, P.O. 58, SUP. 3, 10 septiembre 2016.

16 Véase el Artículo 406 Bis, del Código Civil del Estado de Durango, publicado en los periódicos oficiales no. 7 al 15 de fecha 22 de enero de 1948 al 19 de agosto de 1948, última reforma: dec. 350 p.o. 105 Bis del 31 de diciembre de 2017.

17 Véase el Artículo 473-A, párrafo tercero, del Código Civil para el Estado de Guanajuato, publicado en el Periódico Oficial, el 14 de mayo de 1967, última reforma publicada en el periódico oficial del Gobierno del Estado número 105, segunda parte, de fecha 01 de julio de 2016.

${ }^{18}$ Véase el Artículo 566, fracción III, del Código Civil para el Estado de Jalisco, publicado el 25 de febrero de 1995, última reforma: el 28 de diciembre de 2017.

${ }^{19}$ Véase el Artículo 318, del Código Familiar para el Estado de Michoacán de Ocampo, publicado en la Décima Cuarta Sección del Periódico Oficial del Estado de Michoacán, el miércoles 30 de septiembre de 2015, Última Reforma publicada en el Periódico Oficial del Estado, el 12 de abril 2017, Tomo: CLXVII, número: 5, Octava Sección.

${ }^{20}$ Véase el Artículo 224, del Código Familiar para el Estado Libre y Soberano de Morelos, publicado en el Periódico Oficial el 2006/09/06, Última Reforma: 21-03-2018.

${ }^{21}$ Véase el Artículo 268, párrafo segundo, del Código Civil para el Estado de Nayarit, publicado en la Segunda Sección del Periódico Oficial del Estado de Nayarit, el sábado 22 de Agosto de 1981, última reforma publicada en el Periódico Oficial: 27 de julio de 2017.

${ }^{22}$ Véase el Artículo 411, párrafo tercero, del Código Civil para el Estado de Nuevo León, publicado en el Periódico Oficial, el sábado 6 de Julio de 1935, última reforma publicada en el Periódico Oficial Número 39, del 28 de marzo de 2018.

${ }^{23}$ Véase el Artículo 447, párrafo cuarto, del Código Civil para el Estado de Querétaro, publicado en el Periódico Oficial, el 20 de octubre de 2009, última reforma publicada en el Periódico Oficial el 11 de agosto de 2017. 
maulipas $^{24}$, Veracruz ${ }^{25}$ y Yucatán ${ }^{26}$

No obstante lo ya citado, en México existen pocos estudios relacionados con la alienación parental, siendo las definiciones citadas previamente la base para la aplicación jurídica en México, por lo que son pocos los casos de investigación que se pueden encontrar, destacando entre ellos, la contribución hecha por Lucía Rodríguez Quintero, Licenciada en Derecho por la Facultad de Derecho de la Universidad Nacional Autónoma de México y Subdirectora en el Programa sobre Asuntos de la Niñez y la Familia de la Comisión Nacional de Derechos Humanos, colaboradora en la obra Alienación Parental, publicada por la CNDH en México, en el año 2011, quien se encargó de realizar una definición jurídica novedosa sobre este tema, al mencionar que:

La Alienación Parental se refiere a la conducta llevada a cabo por el padre o madre que conserva bajo su cuidado al hijo(a) y realiza actos de manipulación con la finalidad de que el menor de edad odie, tema o rechace injustificadamente al progenitor que no tiene su custodia legal. ${ }^{27}$

De igual manera, destaca el concepto formulado por el Dr. Ricardo Ruiz Carbonell, Director de Enlace Inter-institucional de la Fiscalía Especial para los Delitos de Violencia contra las Mujeres y Trata de Personas, de la Procuraduría General de la República, quien en la misma obra de Alienación Parental, señala:

[...] obstaculizar el derecho del o la menor a mantener sus vínculos emocionales y afectos con ambos progenitores y familiares por igual, es

\footnotetext{
${ }^{24}$ Véase los Artículos 259, fracción II, 259 Bis, 260, 261, 298 Ter, párrafo tercero, 380, 383, párrafo tercero, del Código Civil Para el Estado de Tamaulipas, publicado mediante Decreto No. 441, del 10 de diciembre de 1986, última reforma publicada en el Periódico Oficial el 13 de diciembre de 2017.

${ }^{25}$ Véase el Artículo 345, párrafo tercero, del Código Civil para el Estado de Veracruz de Ignacio de la Llave, publicado en el suplemento especial de la Gaceta Oficial. Órgano del Gobierno del Estado de Veracruz-Llave, el 15 de septiembre de 1932, última reforma publicada en la Gaceta Oficial: 29 de noviembre de 2016.

${ }^{26}$ Véase el Artículo 280, del Código Familiar del Estado de Yucatán, publicado el 16 de octubre de 2007, última reforma el 28 de diciembre de 2016.

${ }^{27}$ Rodríguez Quintero, Lucía, “Alienación Parental y Derechos Humanos en el Marco Jurídico Nacional. Algunas Consideraciones”, Alienación Parental, 2a․ Edición, Comisión Nacional de Derechos Humanos, México, 2013, p. 65.
} 
una forma de maltrato emocional que puede ocasionarles un daño a su bienestar y desarrollo emocional. ${ }^{28}$

Finalmente, otra de las aportaciones más importantes que podemos encontrar sobre el tema de alienación parental, es la que hace Graciela G. Buchanan Ortega, Magistrada de la Quinta Sala Familiar Unitaria del Tribunal Superior de Justicia del Estado de Nuevo León, quien señala:

[...] la alienación parental es el conjunto de síntomas que resultan del proceso por el cual un progenitor, mediante distintas tácticas o estrategias, intenta transformar la conciencia de sus hijos con objeto de impedir, obstaculizar o destruir sus vínculos con el otro progenitor. Se trata de un proceso gradual y consistente, que invariablemente implica una limitación al progenitor no custodio, en el ejercicio de sus derechos y obligaciones como padre, además de privarlo de la presencia y disfrute de sus hijos. ${ }^{29}$

De este último concepto, pueden sustraerse de forma clara los elementos que integran la alienación parental, siendo estos: Un proceso a través del cual se utilizan tácticas o estrategias para manipular la voluntad de los hijos, con el fin de terminar con los vínculos emocionales que existen entre los hijos y el progenitor alienado. De modo que, al concluir con el proceso de alienación, el menor evitará a toda costa tener algún contacto físico o emocional con su padre o madre, con quien en algún momento mantuvo un fuerte lazo emocional y psicológico.

\section{Características de los sujetos en la aliena- CIÓN PARENTAL}

En el proceso y desarrollo de la alienación parental, hay tres sujetos partícipes:

a) Progenitor/padre o madre alienador.

\footnotetext{
${ }^{28}$ Ruiz Carbonell, Ricardo, "La Llamada Alienación Parental: La Experiencia en España”, Alienación Parental, 2 $2^{\mathrm{a}}$. Edición, Comisión Nacional de Derechos Humanos, México, 2013, p. 151.

${ }^{29}$ Buchanan Ortega, Graciela G., Alienación Parental "Ensayo sobre su trascendencia en el ámbito judicial”, Presidencia del Tribunal Superior de Justicia del Estado de Nuevo León, $1^{\underline{a}}$ edición, 2012, p. 5.
} 
b) Hijo(a) alienado.

c) Progenitor/padre o madre alienado.

Por ello las características que se presentan serán exclusivas de cada uno, sin olvidar que en la individualidad generan una misma consecuencia.

\section{PROGENITOR/PADRE O MADRE ALIENADOR}

$\mathrm{Al}$ respecto, el Dr. José Luis Oropeza Ortiz, docente de la Universidad Nacional Autónoma de México, al citar a Richard Gardner, en su artículo intitulado Síndrome de Alienación Parental Actores Protagonistas, en lo relacionado de los participantes en la alienación parental, refiere:

El primer actor del síndrome es el programador o alienante. Gardner defiende la existencia de una programación mental consciente y situaciones menos explícitas inconscientes.

Parece que esta situación se produce más fácilmente en las relaciones entre madre e hijos, de ahí que un padre programador tenga probablemente menos éxito que una madre programadora. Aunque cada vez se igualan más los porcentajes madre/padre en el SAP.

Algunos comportamientos que se han encontrado en progenitores que están induciendo el Síndrome de Alienación Parental en sus hijos, son:

1. Impiden el contacto telefónico con los hijos.

2. Suelen organizar diferentes actividades con los hijos durante el período que el otro progenitor debe ejercer su derecho de visita.

3. Presentan a su nuevo cónyuge a los hijos como su nueva madre o su nuevo padre.

4. Interceptan el correo y los paquetes enviados a los hijos.

5. Desvalorizan e insultan al otro progenitor delante de los hijos y también en ausencia del mismo.

6. No informan al otro progenitor sobre las actividades que realizan los hijos (deporte, teatro, actividades escolares...).

7. Hablan de manera descortés del nuevo cónyuge del otro progenitor.

8. Impiden al otro progenitor ejercer su derecho de visita. 
9. "Se olvidan" de avisar al otro progenitor de citas importantes del niño con dentistas, médicos, psicólogos, etc.

10. Implican a su entorno (su madre, su nuevo cónyuge, abuelos...) en el lavado de cerebro de los hijos.

11. Toman decisiones importantes sobre los hijos sin consultar al otro progenitor (religión, elección de la escuela).

12. Cambian (o lo intentan) sus nombres o apellidos para que pierdan el del progenitor alienado.

13. Impiden al otro progenitor el acceso a los expedientes escolares y médicos de los hijos.

14. Pueden irse de vacaciones sin los hijos y dejarles con otra persona, aunque el otro progenitor esté deseoso y dispuesto para ocuparse de ellos.

15. Cuentan a los hijos que la ropa que el otro progenitor les ha comprado es fea y les prohíben usarla.

16. Amenazan con castigos a los hijos si se atreven a llamar, escribir o a contactar con el otro progenitor de la manera que sea.

17. Reprochan al otro progenitor los malos comportamientos de los hijos.

18. Ridiculizan los sentimientos de afecto de los niños hacia el otro progenitor.

19. Premian las conductas despectivas y de rechazo hacia el otro padre.

20. Aterrorizan a los niños con mentiras sobre el progenitor ausente, insinuando o diciendo abiertamente que pretende dañarles.

21. Presentan falsas denuncias de abuso (físico y/o sexual) en los tribunales para separar a los niños del otro progenitor.

22. Pueden incluso cambiar de domicilio a muchos kilómetros, con el único fin de destruir la relación del padre ausente con sus hijos.

Hay muchos más comportamientos que nos encontramos en estos casos y que lo único que persiguen es la destrucción total del vínculo de los hijos con el progenitor con el que no conviven, sólo sirva decir que pueden presentarse de muchas maneras, activas o pasivas, pero el resultado es lo que llamamos SAP. ${ }^{30}$

\footnotetext{
${ }^{30}$ Oropeza Ortiz, José Luis, "Síndrome de Alienación Parental Actores Protagonistas”, Revista Internacional de Psicología, Instituto de la Familia Guatemala, [en línea], Vol. 8, ISSN 1818-1023, N² 2, julio, 2007, pp. 2-3, [fecha de consulta: 27 de febrero de 2018], disponible en:

<http://www.revistapsicologia.org/index.php/revista/article/download/47/44>.
} 
Sobre este tema, el Dr. Douglas Darnall, realizó una clasificación para diferenciar los niveles o tipos de progenitores alienadores:

[...] La prevención o el freno de la alineación pueden comenzar enseñando como reconocer los tres tipos de alienadores, ya que los síntomas y estrategias para combatir cada una de ellas, son diferentes.

Los Alienadores Simples son progenitores que ocasionalmente harán o dirán algo alienante. Todos los progenitores serán ocasionalmente alienadores Simples.

Los Alienadores Activos no solo conocen también mejor como alienar, sino que su intensa herida y rabia, le lleva a una pérdida impulsiva del control sobre su comportamiento, o sobre lo que dicen. Más tarde, se pueden sentir muy culpables, sobre su comportamiento.

Los Alienadores Obsesivos tienen una ferviente causa, para destruir al progenitor Diana. Con frecuencia un progenitor puede ser una combinación de Alienador Simple y Alienador Activo. Raramente los alienadores obsesivos tienen suficiente autocontrol o introspección para mezclarse con los otros tipos. ${ }^{31}$

De la clasificación realizada por el Dr. Douglas Darnall, podemos observar el establecimiento de tres tipos de progenitores alienadores, que se diferencian por actitudes sumamente marcadas, que son muy importantes en el grado de afectación que puedan provocar en los menores; los alienadores simples son ocasionales, por lo general saben y reconocen sus equivocaciones, se centran en lo que es bueno para los hijos, sin remordimiento, daño o martirio para sí mismos; por el contrario, los alienadores activos son impulsivos y pierden el control sobre su comportamiento, para después sentirse culpables y apenados por los comentarios o acciones realizadas, generalmente están dispuestos a aceptar ayuda profesional; por último, los alienadores obsesivos, tienen una ferviente causa para "destruir" al progenitor alienado, tienen una insaciable rabia, porque ellos creen que el padre alienado les ha convertido en víctimas, y cualquier cosa que ellos hagan para proteger a los hijos está justificada.

${ }^{31}$ Cfr. Douglas Darnall, Ph. D, “Tres tipos de PAS”, APADESHI Asociación de padres Alejados de sus Hijos, [en línea], [fecha de consulta: 27 de febrero de 2018], disponible en: <http://sindromedealienacionparental.apadeshi.com/tres_tipos_de_ pas douglas_darn.htm>. 
Al respecto, el Dr. José Luis Oropeza Ortiz en lista una serie de características que deben evaluarse para identificar a un menor alienado:

[...] El primero es la existencia de una campaña de denigración, en la cual el niño continuamente manifiesta su odio al padre ausente.

Existen racionalizaciones triviales, frívolas o absurdas para despreciar al padre "alienado". El niño justifica la alienación con recuerdos de pequeños altercados experimentados con el padre rechazado, da pretextos fútiles, poco creíbles o absurdos para justificar su actitud. Un ejemplo de este aspecto es cuando un niño que decía no querer visitar a su padre porque "no me dejó un folio para dibujar."

El tercer síntoma es la falta de ambivalencia tanto en el padre alienante como en el niño alienado. En los niños se manifiesta en que no pueden ver nada bueno en el padre alienado, y nada malo en el padre amado. Se insiste en que la decisión de rechazar al padre corresponde al niño. Gardner (1992) se refiere a este hecho como el "Fenómeno del Pensador Independiente”. El propio niño defenderá que la decisión es propia, logrando supuestamente liberar de la culpa al progenitor alienante y protegerle de las críticas.

En quinto lugar se produce un apoyo automático del hijo hacia el padre amado, aspecto relacionado con la falta de ambivalencia ya antes descrita. El niño apoyará al $100 \%$ los postulados del padre, e incluso ante la evidencia contraria mantendrá su adhesión al criterio del programador. Existe una casi completa ausencia de culpa hacia los sentimientos del padre rechazado. No existe gratitud por sus regalos, favores o apoyos. Aparecen escenarios prestados, con una letanía que parece aprendida, y que incluye frases del padre amado. Cabe fijarse en el vocabulario que se emplea que es impropio de un niño, usando palabras que puede desconocer.

Por último, aparece una extensión del odio a la familia del padre rechazado y/o a los amigos del padre rechazado. Como un virus, el SAP puede extenderse y contaminar a todos los miembros de la familia del progenitor odiado. Los tíos, primos, abuelos, con los que anteriormente habían mantenido una buena relación ahora son vistos como "repugnantes y odiosos” y no hay ningún deseo de relacionarse con ellos, con la impor- 
tante pérdida de estimulación y afecto que puede suponer también. ${ }^{32}$

Las características descritas anteriormente, revelan el mecanismo de cómo se desarrolla y comporta un menor que se encuentra sometido a la alienación parental. Como ya se explicó, la campaña de manipulación que resulta ser uno de los elementos más importantes de la alienación parental, tiene como particularidad que el menor aprende a menospreciar al padre o madre alienado, que se convierte para él, en algo más que un enemigo, es un total desconocido que con su presencia provoca agresión al menor.

Al respecto, el psicólogo Aguilar Cuenca, en su obra El Síndrome de Alienación Parental, se encargó de describir el desarrollo de la campaña de denigración que hemos venido señalando, al respecto, refiere:

[...] La campaña de denigración tiene dos componentes: el adoctrinamiento recibido por el progenitor y, en un momento posterior, las propias contribuciones de los niños. Cuando la campaña de desprestigio ha enraizado en el menor, este aporta argumentos a los ataques que son elaboraciones propias.

La dinámica de este proceso requiere, por tanto, la construcción de razones o justificaciones que permitan injuriar al progenitor rechazado. Una estrategia muy útil es tomar prestadas las razones del alienador, que el menor hace propias.

Algunos autores defienden que esta estrategia de identificación con el alienador es una forma de escapar a la posibilidad de ser ellos mismos víctimas del acoso. Sea como sea, los menores inician este proceso afirmando su superioridad ante el progenitor alienador en una actitud retadora: "Tú no eres nadie para mandarme", que viene apoyada por el otro progenitor: "Mi madre me ha dicho que si no quiero hacer algo no lo haga", para proseguir con amenazas: "Si me tocas un pelo llamo a la policía, o directamente los insultos: “¿Qué vienes de ver a esa puta? El progenitor alienado va comprendiendo que apenas puede manejar la situación y controlar los deseos de su hijo pequeño. El niño muestra un

${ }^{32}$ Oropeza Ortiz, José Luis, op. cit., nota 12, pp. 6-7. 
comportamiento cada vez más tirano: "No se te olvide ingresar la pensión alimenticia en el banco de mamá”. ${ }^{33}$

De lo expuesto por el psicólogo José Manuel Aguilar, es posible establecer que, la campaña de denigración se realiza de manera secuencial; una vez presente la alienación parental, el menor comienza a actuar por sí mismo en los ataques, asume un papel activo en el que el padre alienado es un simple desconocido, del que su sola presencia puede molestarle. Todos los padres conocen a sus hijos, lo que pueden esperar y lo que no de ellos, pero, ¿Qué pasa cuando se empieza a romper el contacto con ellos, cuando un hijo exige, reclama o crea falsas acusaciones? ¿Qué dio origen a esas conductas?

En cuanto a las justificaciones, ya se mostró que éstas son sencillas e irrelevantes, el menor deforma convenientemente lo que vive con el padre alienado para poder apoyar el rechazo con el alienador, esta deformación va incrementándose y va acompañada de un lenguaje que no siempre es propio del menor, va siendo más revelador con el paso del tiempo, el contacto visual disminuye y sobre todo la distancia física aumenta.

De esta forma, al conocer las características que identifican al padre o madre alienador y al menor alienado, se puede concluir que el progenitor alienado sufre el rechazo en niveles, conforme al desarrollo de la conducta de alienación que se realice.

\section{PROGENITOR/PADRE O MADRE ALIENADO}

Sobre los comportamientos clásicos de un progenitor alienado, el Dr. José Luis Oropeza describe lo siguiente:

El padre alienado ha recibido menos atención y es peor comprendido por todos los autores. Gardner le muestra como pasivo. Otros autores le consideran responsable del abandono e infidelidad, debido a su negligencia.

El padre alienado está confuso y se siente culpable, la mayoría se reco-

${ }^{33}$ Aguilar Cuenca, José Manuel, Síndrome de Alienación Parental, Editorial Síntesis, España, 2013, p. 52. 
noce como víctima, está muy frustrado por su impotencia ante la manipulación y haga lo que haga no puede vencer, si lucha es un acosador, si se retira es un negligente.

La actitud más frecuente del padre alienado es el silencio, pensando que ellos no van a repetir el mismo error del programador. Debe entenderse que es importante para el niño conocer la realidad para poder superar la programación. Creer que el niño va a llegar solo a una conclusión independiente es completamente ingenuo. ${ }^{34}$

Respecto a este último sujeto, quien forma parte de los tres elementos que constituyen la alienación parental, no se ha hablado mucho, no se encuentra casi ninguna información de respecto de las características que presenta, así como de su comportamiento, que quizá podría influir o aumentar la actitud hostil del menor.

Su comportamiento es como un espejo del padre alienador, con denotación contraria, ya que es éste quien recibe toda la carga negativa, pero que más allá de caer rendido por la conducta que ejerce el alienador, busca la salida; sin embargo, en ocasiones también es portador de comportamientos negativos, consecuencia de la alienación de la que es objeto; no obstante a ello, se reitera que no es la única y principal víctima, ya que es el menor quien se encuentra afectado en sus emociones, al ser manipulado y utilizado durante las disputas entre sus padres.

Finalmente, después de haber analizado los elementos que constituyen la alienación parental, así como las características de cada uno de los sujetos que intervienen en ella; es posible concluir que, la conducta de alienación parental, se presenta no como un síndrome, sino como un fenómeno social existente y diagnosticable; es decir, se trata de actos dirigidos a manipular al menor a fin de provocar en él, sentimientos de desprecio, desaprobación, odio, rencor, miedo o rechazo hacia a alguno de sus padres, lo cual si bien tiene influencia en la psique del menor, no anula su conciencia, ni genera en él/ella trastornos mentales; por lo que no es necesario su reconocimiento

$\overline{34}$ Oropeza Ortiz, José Luis, op. cit., nota 12, p. 9. 
científico, ya que se cuenta con elementos suficientes que permiten su análisis desde un punto de vista psicológico, sociológico y jurídico; lo que permite demostrar su existencia y el impacto que genera en la estabilidad emocional de los menores.

Por tanto, preexiste la necesidad de legislar y unificar criterios en todo nuestro país respecto de la alienación parental, así como establecer medidas que eliminen su desarrollo dentro de los núcleos familiares, así como en las controversias jurisdiccionales relacionadas con menores, máxime las repercusiones que pueden tener en el menor y por tanto en su desarrollo emocional y personal, por lo que si uno de los pilares de nuestra sociedad es la protección a la familia y la protección del interés superior de los menores, resulta más que evidente que debe existir una regulación que sancione, proteja y establezca la alienación parental de manera clara y precisa.

III. DECRETO POR EL QUE SE DEROGA EL ARTÍCULO 323 SÉPTIMUS DEL CÓDIGO CIVIL DEL DISTRITO FEDERAL Y LA ACCIÓN DE INCONSTITUCIONALIDAD 1 1/2016

El 4 de agosto de 2017, se publicó en la Gaceta Oficial de la Ciudad de México, el Decreto por el que se deroga el artículo 323 Séptimus del Código Civil del Distrito Federal, ${ }^{35}$ que contenía la figura denominada "alienación parental", donde era considerada un tipo de violencia familiar; como ya lo referimos, dicha actividad consiste en la acción de uno de los integrantes de la familia para manipular la voluntad de un menor con el objeto de impedir, obstaculizar o destruir sus vínculos con uno de sus progenitores. De este modo, para que pudiera considerarse alienación, era necesario que la conducta fuera realizada por uno de los padres, y una vez acreditada, era posible suspender el ejercicio de la patria potestad del menor y, en

${ }^{35}$ Gaceta Oficial de la Ciudad de México, publicada el 4 de agosto de 2017, [en línea], [fecha de consulta: 27 de febrero de 2018], disponible en:

<http://data.consejeria.cdmx.gob.mx/portal_old/uploads/gacetas/37de4769c776616bfdb182dc53f08ba7.pdf> 
consecuencia, del régimen de visitas y convivencias que, en su caso, tuviera decretado.

Asimismo, en caso de que el padre alienador tuviera la guarda y custodia del niño, ésta pasaría de inmediato al otro progenitor, si se tratare de un caso de alienación leve o moderada. En el supuesto de que el menor presentara un grado de alienación parental severo, en ningún caso, permanecería bajo el cuidado del progenitor alienador o de la familia de éste, se suspendería todo contacto con el padre alienador y el menor sería sometido al tratamiento que indicara el especialista que hubiera diagnosticado dicho trastorno. ${ }^{36}$

Dentro de los argumentos considerados en la iniciativa aprobada por la Asamblea Legislativa del Distrito Federal (ALDF), se destacan los siguientes:

1. El supuesto síndrome de alienación parental utiliza para detectar su presencia los mismos indicadores utilizados para detectar la violencia o abuso sexual, por lo anterior impide identificar cuando efectivamente suceden.

2. Se viola el principio de precaución, toda vez que se introduce un

${ }^{36}$ Artículo 323 Séptimus.- Comete violencia familiar e integrante de la familia que transforma que transforma la conciencia de un menor con el objeto de impedir, obstaculizar o destruir sus vínculos con uno de sus progenitores.

La conducta descrita en el párrafo anterior, se denomina alienación parental cuando es realizada por uno de los padres, quien, acreditada dicha conducta, será suspendido en el ejercicio de la patria potestad del menor y, en consecuencia, del régimen de visitas y convivencias que, en su caso, tenga decretado. Asimismo, en caso de que el padre alienador tenga la guarda y custodia del niño, ésta pasará de inmediato al otro progenitor, si se trata de un caso de alienación leve o moderada.

En el supuesto de que el menor presente un grado de alienación parental severo, en ningún caso, permanecerá bajo el cuidado del progenitor alienador o de la familia de éste, se suspenderá todo contacto con el padre alienador y el menor será sometido al tratamiento que indique el especialista que haya diagnosticado dicho trastorno.

A fin de asegurar el bienestar del menor, y en caso de que, por su edad, resulte imposible que viva con el otro progenitor, el departamento de psicología del Tribunal Superior de Justicia del Distrito Federal, evaluando a los parientes más cercanos del niño, determinará qué persona quedará encargada de su cuidado; mientras recibe el tratamiento respectivo que haga posible la convivencia con el progenitor no alienador. El tratamiento para el niño alienado será llevado a cabo en el Departamento de Alienación Parental del Servicio Médico Forense del Tribunal Superior de Justicia del Distrito Federal. 
concepto que carece de consenso en la comunidad psiquiátrica.

3. La alienación se correlaciona fuertemente con la violencia de género, toda vez que la mayoría de denuncias por violencia en contra de niñas, niños y adolescentes es interpuesta por mujeres.

4. Trasciende y afecta la convivencia con sus madres o padres y al consentimiento en la toma de decisiones que afectan a niñas y niños.

5. Afecta la Patria Potestad sin determinación judicial ex ante, por lo que vulneran los derechos de las partes involucradas.

6. No incorpora el Principio de Proporcionalidad, el cual es necesario para la limitación o restricción de derechos, lo anterior toda vez que las posibles ventajas que pudieran obtener con la norma no guardan relación con las consecuencias de su aplicación. ${ }^{37}$

Como puede observarse, la Asamblea Legislativa consideró que los indicadores establecidos para la detección del síndrome de alienación parental, son los mismos que se utilizan para la detección de violencia y abuso sexual; por lo que, según su razonamiento el reconocimiento de la figura de alienación parental, impide la detección oportuna de los casos reales de abuso; asimismo, destacó la falta de consenso entre la comunidad psiquiátrica respecto de que la alienación parental sea un síndrome, además de contribuir indirectamente al aumento de la violencia de género.

Por su parte, la Comisión de Derechos Humanos del Distrito Federal (CDHDF), así como algunas organizaciones de la sociedad civil, y defensoras de los derechos humanos de la infancia y las mujeres, sostienen que dicha norma formalizaba una discriminación indirecta y reproducía estereotipos basados en el género en perjuicio de las mujeres, siendo causa y consecuencia de la violencia institucional en su contra; además no reconocía la autonomía progresiva de las niñas y niños.

${ }^{37}$ Proposición con punto de acuerdo, por el que se exhorta respetuosamente a diversas autoridades a revisar la figura del síndrome de alienación parental preponderando el interés superior de la niñez. [en línea], [fecha de consulta: 01 de marzo de 2018], disponible en: <http:/www.senado.gob.mx/sgsp/gaceta/63/2/2017-(08-16-1/ assets/documentos/PA_PRD_Alienacion_Parental.pdf $>$. 
La CDHDF se pronunció a favor de la decisión tomada por la Asamblea Legislativa del Distrito Federal, al derogar el artículo 323 Séptimus del Código Civil del Distrito Federal, por considerar que la figura del "síndrome de alienación parental (SAP)", es un tipo de violencia inexistente como síndrome ya que carece de sustento y reconocimiento científico, además que desconoce a niñas y niños como personas sujetas plenas de derechos, ya que omite la importancia de tomar su opinión en cuenta para la toma de decisiones a partir de su autonomía progresiva, en particular en los casos de conflicto parental. $^{38}$

En esa misma línea, la Defensoría de los Derechos Humanos del Pueblo de Oaxaca, demandó ante la Suprema Corte de Justicia de la Nación (SCJN), la invalidez de los artículos 336 Bis B, en relación con el segundo párrafo del artículo 429 Bis A y 459 fracción IV, del Código Civil para el Estado de Oaxaca, reformados y adicionados mediante Decreto 1380, publicado en el Periódico Oficial de esa entidad el 2 de enero de 2016; que conformó la Acción de Inconstitucionalidad $\mathrm{N}^{\circ}$ 11/2016. El accionante, en esencia, alegó que dichos numerales transgredían los derechos de los niños, niñas y adolescentes para expresar su opinión en los procedimientos que los involucren, se soslayaba la obligación de juzgar y legislar con perspectiva de género, asimismo, estimó que dicha incorporación normativa del síndrome de alienación parental, resultaba incompatible con el interés superior del menor.

Por lo que, el 24 de octubre de 2017, el Tribunal en Pleno de la Suprema Corte de Justicia de la Nación por mayoría de nueve votos, determinó declarar la invalidez del artículo 336 Bis B, último párrafo, así como de la fracción IV, del numeral 459; de la misma manera pero con una mayoría de ocho votos, se declaró la invalidez del artículo

${ }^{38}$ Cfr. Comisión de Derechos Humanos del Distrito Federal,[en línea], [fecha de consulta: 27 de febrero de 2018], disponible en: <https://cdhdf.org.mx/2017/08/ la-cdhdf-reconoce-la-proteccion-de-los-derechos-humanos-a-traves-de-la-derogacion-de-la-mal-denominada-figura-de-alienacion-parental-del-codigo-civil-de-la-ciudadde-mexico/>. 
429 Bis A, párrafo primero en la porción normativa que establece: "bajo pena de suspenderse o declararse la pérdida de su ejercicio", todos del Código Civil para el Estado de Oaxaca.

Finalmente, se reconoció la validez del artículo 429 Bis A, que señala: "Quien tenga el cuidado y custodia de los hijos debe procurar el respeto y el acercamiento constante de los menores con el otro ascendiente que también ejerza la patria potestad; en consecuencia, cada uno de los ascendientes deberá evitar cualquier acto de alienación parental, encaminado a producir en el menor rechazo, rencor, odio, miedo o desprecio hacia el otro progenitor. [...]. Se entiende por alienación parental la manipulación o inducción que un progenitor realiza hacia su hijo, mediante la desaprobación o crítica tendiente a producir en el menor rechazo, rencor, odio, miedo o desprecio hacia el otro progenitor." Lo anterior, con excepción de la parte declarada inconstitucional, mediante una votación a favor de 6 Ministros.

El pronunciamiento de la Suprema Corte de Justicia de la Nación, atendió esencialmente a los siguientes argumentos:

[...] a fin de brindar un panorama más amplio, la Sala dividió el estudio del asunto en los siguientes apartados: i) Estudio del fenómeno denominado alienación parental, ii) Derechos humanos de los niños, niñas y adolescentes, iii) Estudio de los conceptos de invalidez, el cual dividió en dos bloques principales y así como el estudio de la regularidad constitucional de las normas combatidas.

De esa manera, el Tribunal en Pleno determinó en principio, que la conducta regulada normativamente, no se refería al "síndrome de alienación parental" derivado de la teoría psicológica expuesta por Richard Gardner, sino que el legislador atendió a múltiples referencias teóricas que generan un panorama de mayor amplitud sobre dicha cuestión, no como síndrome, sino como un fenómeno existente y diagnosticable, en el cual se distinguen conductas o acciones de rechazo que un hijo presenta hacia uno de sus padres, así como la utilización del o de los hijos en el conflicto parental de separación, como medio de expresión de odio o de venganza entre los progenitores.

De igual manera, los Ministros indicaron que la conducta legislada en el 
Código Civil en comento, no reproduce estereotipos de género, ni soslaya la obligación de legislar con perspectiva de género, toda vez que no hace distinción de trato entre los padres o alguno de los familiares que pudiera encuadrase en la discriminación por razón de género, ya que cualquiera puede figurar como sujeto activo de la conducta.

Por otra parte, se abordó el análisis de la conducta de alienación parental, como un supuesto de violencia familiar, el cual se encuentra regulado en el artículo 336 Bis B, párrafo tercero. Sobre éste el Pleno se pronunció en el sentido de declarar que dicho precepto vulnera los derechos de los menores de edad al estimar que las conductas efectuadas en su contra, producen como resultado la "transformación de su conciencia”, transgrediendo su derecho a ser considerados sujetos con autonomía progresiva; asimismo, dicho resultado conlleva a afectar su derecho a ser escuchado en los procedimientos jurisdiccionales en los que se les involucre, toda vez que al establecer que su conciencia ha sido modificada, se menoscaba intrínsecamente su autonomía induciendo tanto a los operadores judiciales, como a los peritos en psicología a considerar que la opinión del menor se encuentra viciada y por ende, no tomarla suficientemente en cuenta.

De igual forma, estudiando el supuesto de violencia familiar, se avocaron al examen del numeral 429 Bis A de la normatividad en cita, en donde el Pleno determinó que dicha disposición no vulnera los derechos de los menores, ya que la conducta descrita no contempla la exigencia del resultado de "transformar la conciencia" del menor, ya que la legislación prevé únicamente los actos dirigidos a manipular al menor a fin de provocar en él, sentimientos de desprecio, desaprobación, odio, rencor, miedo o rechazo hacia a alguno de sus padres, lo cual si bien tiene influencia en la psique del menor, no anula su conciencia, por lo tanto la norma combatida fue calificada de constitucional.

En lo relativo al numeral 429 Bis A, última parte, en relación con la fracción IV, del artículo 459, ambos del código combatido, los ministros determinaron que ante el acreditamiento de la conducta de alienación parental, imponen a manera de sanción la suspensión o pérdida de la patria potestad, sin embargo, la Corte en el Pleno, se pronunció en el sentido de declararlos inconstitucionales, toda vez que por una parte, se estimó que 
condicionar el ejercicio de la patria potestad a una sanción, no constituye un acto de protección reforzada a los derechos de los menores, sino que implícitamente se tolera dicha violencia, lo cual rompe con los estándares convencionales y constitucionales a que ésta constreñido el Estado Mexicano. Mientras que por la otra, transgreden el principio de proporcionalidad pues impone al juzgador una aplicación irrestricta en todos los casos, sin permitirle un margen adecuado para que éste pudiera valorar idóneamente las circunstancias especiales de cada asunto en particular, lo cual puede reflejarse en la violación del derecho de los menores a vivir dentro de una familia, ya que si la conducta desplegada se acredita como alienación parental, el juzgador se vería obligado a decretar la separación del padre que la ejerza y por tanto, impedir de manera natural el mantenimiento de las relaciones afectivas entre éstos. [... $]^{39}$

Durante el análisis expuesto, la SCJN anunció la validez del reconocimiento de la existencia de la alienación parental, como un fenómeno social, perfectamente diagnosticable; en el cual se distinguen conductas o acciones de rechazo que un hijo presenta hacia uno de sus padres, así como la utilización del o de los hijos en el conflicto parental de separación, como medio de expresión de odio o de venganza entre los progenitores. Asimismo, sostuvo la necesidad de regular esta conducta, así como unificar criterios en cada una de las Entidades Federativas de nuestro país.

\section{TRATO LEGISLATIVO}

\section{OMISIÓN LEGISLATIVA, SU CONCEPTO}

La autora Laura M. Rangel Hernández, en su artículo intitulado El control de las omisiones legislativas en México. Una invitación a la reflexión, realiza una exposición breve y clara del concepto de omisión legislativa, que ilustra cada uno de los elementos que la constituyen, misma que a nuestro entender, tiene aplicación en el presente trabajo:

\footnotetext{
39 CRÓNICAS DEL PLENO Y DE LAS SALAS, [en línea], disponible en: $<$ https://www.scjn.gob.mx/sites/default/files/sinopsis_asuntos_destacados/documento/2017-12/TP-241017-NLPH-0011.pdf>.
} 
La omisión legislativa [...] Tiene su fundamento en la existencia de un mandato para legislar que, ya sea de forma implícita o expresa, se encuentra contendido en la norma fundamental y que ha sido desatendido por el legislador ordinario, con lo cual se causa la irregularidad del orden jurídico y en muchos casos la indefensión o falta de certeza jurídica hacia los gobernados. $\mathrm{Al}$ respecto, cabe destacar que sólo en forma excepcional el constituyente establece un plazo específico para la producción de las normas de desarrollo constitucional, y mayoritariamente se deja esto indefinido; este tema es el que configura uno de los puntos débiles o que plantean mayor dificultad para la determinación de las omisiones de tipo legislativo y la posibilidad de su calificación de inconstitucionales, debido a que será a través de cada caso concreto donde se determine que ha transcurrido un lapso "excesivo" de tiempo para que pueda hablarse de "mora legislativa".

Tradicionalmente, la omisión legislativa se ha estudiado desde dos puntos de vista: como absoluta y relativa. Esta clasificación fue elaborada y estudiada por Wessel, y se resume en que la primera existe cuando hay una "ausencia total de desarrollo de un precepto constitucional" y la segunda cuando se trata de la "vulneración del principio de igualdad por olvido de ciertos grupos en la legislación”. Cabe destacar que, para dicho autor, esta última puede reconducirse a una inconstitucionalidad de tipo positivo que sí se puede confrontar con la Constitución. Así también se ha distinguido entre las omisiones del legislador, que son las que aluden a las de tipo relativo porque la ley se emitió para reglar una materia específica pero se hizo de forma incompleta al callar algo que debió contener, y las omisiones de ley, que son las absolutas porque, en realidad no se ha regulado la materia respectiva. ${ }^{40}$

Por su parte, Carlos Báez Silva, define a la omisión legislativa, de la siguiente forma:

${ }^{40}$ Rangel Hernández, Laura M., "El control de las omisiones legislativas en México. Una invitación a la reflexión”, La ciencia del derecho procesal constitucional. Estudios en homenaje a Héctor Fix-Zamudio en sus cincuenta años como investigador del derecho, t. VIII, Procesos constitucionales orgánicos, México, UNAM, Instituto de Investigaciones Jurídicas, p. 4, disponible en: <https://archivos.juridicas.unam.mx/www/bjv/libros/6/2553/26.pdf>. 
[...] Cuando se hace referencia a la omisión del legislador, por tanto, se pretende indicar que éste "no ha actuado como se esperaba", que la conducta probable que se esperaba de él no se ha presentado. ¿Qué conducta, empírica y normativamente probable, se esperaba del legislador? Pues, esencialmente, que legisle, que dicte textos normativos con el carácter de leyes. Así, la expresión "omisión del legislador" denota que el facultado para dar o crear la ley no ha ejercido tal facultad, no ha creado alguna ley (o lo ha hecho insuficientemente) cuando era probable que lo hiciera.

¿Cuándo era probable que el legislador legisle? Dentro del Estado de derecho un órgano del poder político únicamente puede actuar previa autorización constitucional para ello, así que las Cámaras Legislativas sólo pueden legislar cuando están facultadas para ello y en las materias que la propia constitución señale. ${ }^{41}$

Ambas definiciones señalan los elementos esenciales que constituyen una omisión legislativa, los cuales consisten en la existencia de un mandato constitucional para legislar, que puede ser implícito o expreso, y que finalmente ha sido ignorado o desatendido por el legislador; dichas omisiones pueden ser clasificadas como absolutas y relativas.

\section{CLASIFICACIÓN DE LAS OMISIONES LEGISLATIVAS}

En nuestro país, la Suprema Corte de justicia de la Nación, a través de la Tesis Jurisprudencial P./J. 11/2006 ${ }^{42}$,derivada de la Controversia Constitucional 14/2005; estableció que en atención al principio de división funcional de poderes, los órganos legislativos del Estado cuentan con facultades o competencias de ejercicio potestativo y de ejercicio obligatorio, y en su desarrollo pueden incurrir en diversos tipos de omisiones:

\footnotetext{
${ }^{41}$ Báez Silva, Carlos, "La omisión legislativa y su inconstitucionalidad en México”, En busca de las normas ausentes, 2a. ed., Ensayos sobre inconstitucionalidad por omisión, en Miguel Carbonell (Coord.), México, UNAM, Instituto de Investigaciones Jurídicas, pp. 16-17, disponible en: 〈https://archivos.juridicas.unam.mx/www/bjv/libros/5/2455/10.pdf>.

${ }^{42}$ Cfr. Semanario Judicial de la Federación y su Gaceta, t. XXIII, Febrero de 2006 , Tesis: P./J. 11/2006, p. 1527.
} 


\section{OMISIÓN ABSOLUTA}

La omisión absoluta, se presenta cuando los órganos legislativos simplemente no han ejercido su competencia de crear leyes, ni han externado normativamente voluntad alguna para hacerlo.

\section{OMISIÓN RELATIVA}

La omisión relativa, se actualiza cuando al haber ejercido su competencia, los órganos legislativos lo hacen de manera parcial o simplemente no la realizan integralmente, impidiendo el correcto desarrollo y eficacia de su función creadora de leyes.

Ahora bien, combinando ambos tipos de competencias o facultades -de ejercicio obligatorio y de ejercicio potestativo-, y de omisiones -absolutas y relativas-, pueden presentarse las siguientes omisiones legislativas:

1. Absolutas en competencias de ejercicio obligatorio, cuando el órgano legislativo tiene la obligación o mandato de expedir una determinada ley y no lo ha hecho;

2. Relativas en competencias de ejercicio obligatorio, cuando el órgano legislativo emite una ley teniendo una obligación o un mandato para hacerlo, pero lo realiza de manera incompleta o deficiente;

3. Absolutas en competencias de ejercicio potestativo, en las que el órgano legislativo decide no actuar debido a que no hay ningún mandato u obligación que así se lo imponga; y,

4. Relativas en competencias de ejercicio potestativo, en las que el órgano legislativo decide hacer uso de su competencia potestativa para legislar, pero al emitir la ley lo hace de manera incompleta o deficiente.

VI. PROPUESTA PARA UNA EFECTIVA REGULACIÓN DE LA ALIENACIÓN PARENTAL

1. LA APLICACIÓN DE MEDIDAS O SANCIONES, COMO UNA FORMA DE ERRADICAR LA PRÁCTICA DE ALIENACIÓN PARENTAL

En el tema que nos ocupa, es importante señalar que, tal y como se desprende del análisis realizado por nuestro máximo Tribunal, si bien 
es cierto que determinó que la alienación parental no es un síndrome y que no se puede "condicionar el ejercicio de la patria potestad a una sanción, ya que esto vulnerario los derechos del menor” y ocasionaría un menoscabo a su desarrollo y a la sana convivencia de los progenitores, aunado a que sancionar la conducta sería "tolerar la misma", también lo es, que reconoció que existe dicha figura como "un fenómeno social, perfectamente diagnosticable; en el cual se distinguen conductas o acciones d e rechazo que un hijo presenta hacia uno de sus padres, así como la utilización del o de los hijos en el conflicto parental de separación, como medio de expresión de odio o de venganza entre los progenitores”.

Por lo que, al haberse pronunciado incluso bajo el supuesto de la "necesidad de regular esta conducta, así como unificar criterios en cada una de las Entidades Federativas de nuestro país”, resulta más que claro que emitió una sugerencia perfectamente válida para que el legislador en el ejercicio de sus funciones, pudiera legislar protegiendo al menor del uso que los progenitores hagan respecto de la alienación parental y en su caso, tomar algunas medidas para prevenirlo o mejor dicho tratarlo , supuesto que no aconteció por la Asamblea Legislativa, en donde sólo se limitó a derogar el artículo.

En este mismo sentido, resulta cuando la Suprema Corte de Justicia de la Nación al declarar inconstitucional los artículos 323 Séptimus del Código Civil del Distrito Federal, así como los artículos 336 Bis B, en relación con el segundo párrafo del artículo 429 Bis A y 459 fracción IV, del Código Civil para el Estado de Oaxaca, derivó en que las legislaturas respectivas optaron por derogar dichos artículos, es más que claro que se realizó una omisión grave en tal sentido, toda vez que si es una figura que existe y que se ha reconocido que se da de manera práctica, jurídicamente hablando debe de regularse, máxime que son conductas que afectan a menores de edad y a la familia como núcleo de la sociedad, por lo cual el no hacerlo, es una falla legislativa clara y que deja en total estado de indefensión a los progenitores y a los menores que la sufren. 
Así las cosas, es evidente que la omisión ya referida, debe de subsanarse mediante una regulación clara y precisa respecto del llamado "síndrome" de alienación parental, máxime que si insistimos es recurrente en menor o mayor grado acorde a lo ya planteado anteriormente.

En tal sentido, el simple supuesto que se hubieren declarado inconstitucionales los preceptos antes referidos, no debía originar en la derogación absoluta de los mismos, sino por el contrario, al haber reconocido nuestro máximo Tribunal que es una conducta que se da en el mundo fáctico, es evidente que las legislaturas locales, debían de realizar un estudio concienzudo respecto de cómo proteger a los menores de progenitor o pariente que haga uso de la alienación parental, así como el buscar los elementos que puedan prevenirlo o en su caso solucionar la problemática, máxime si insistimos afecta de manera directa a los menores de edad, motivo suficiente por el cual debe de legislarse buscando la protección de éstos.

En este mismo tenor, resulta claro el hecho que las Entidades Federativas al haber omitido entrar al fondo del estudio del llamado "síndrome de alienación parental" a fin de tratar de prevenir o solucionar el mismo, es claro que dejó en estado de indefensión tanto a los menores como a los padres que sufren la repercusión de la conducta, motivo por el cual es preciso solventar dicha situación regulando la ésta, buscando salvaguardar los intereses tanto de los menores como de quien la sufre de manera directa o indirectamente, y si bien no debe ser sancionada por las causad que determinó la Corte, si es preciso prevenirla o bien tratarla en beneficio de la institución de la familia y de los menores que la sufran.

\section{FUENTES}

\section{BIBLIOGRAFIA}

AGUILAR, José Manuel, Síndrome de Alienación Parental, 5ํㅡㄹ Ed., Madrid, Almuzara, S.L., 2006, 214 pp. 
AGUILAR CUENCA, José Manuel, Síndrome de Alienación Parental, Madrid, Sintesis, S.A., 2013, 166 pp.

BUCHANAN ORTEGA, Graciela G., Alienación Parental, Ensayo sobre su Trascendencia en el Ámbito Judicial, Monterrey N.L., Poder Judicial del Estado de Nuevo León, 2012, 120 pp.

RODRÍGUEZ QUINTERO, Lucía, “Alienación Parental y Derechos Humanos en el Marco Jurídico Nacional. Algunas Consideraciones”, Alienación Parental, 2 ${ }^{a}$. Edición, Comisión Nacional de Derechos Humanos, México, 2013.

RUIZ CARBONELL, Ricardo, "La Llamada Alienación Parental: La Experiencia en España”, Alienación Parental, 2ª . Edición, Comisión Nacional de Derechos Humanos, México, 2013.

TEJEDOR HUERTA, Asunción, El Síndrome de Alienación Parental, Una forma de maltrato, Madrid, EOS, 2006, EOS Psicología Jurídica, 155 pp.

VACCARO, Sonia y BAREA Consuelo, El Pretendido Sindrome de Alienación Parental, un Instrumento que Perpetúa el Maltrato y la Violencia, Bilbao, DESCLÉE DE BROUWER, S.A., 2009, 181 pp.

\section{LEGISLACIÓN}

Código Civil del Estado de Aguascalientes, publicado en el Suplemento al No. 49 del Periódico Oficial del Estado de Aguascalientes, el 7 de diciembre de 1947.

Código Civil para el Estado Libre y Soberano de Baja California Sur, publicado en el Boletín Oficial del Gobierno del Estado de Baja California Sur el 19 de Julio de 1996.

Código Civil para el Estado de Colima, publicado en el Suplemento del Periódico Oficial "El Estado de Colima”, el 25 de Septiembre de 1954.

Código Civil del Estado de Durango, publicado en los periódicos oficiales no. 7 al 15 de fecha 22 de enero de 1948 al 19 de agosto de 1948. 
Código Civil para el Estado de Guanajuato, publicado en el Periódico Oficial, el 14 de mayo de 1967.

Código Civil para el Estado de Jalisco, publicado el 25 de febrero de 1995.

Código Familiar para el Estado de Michoacán de Ocampo, publicado en la Décima Cuarta Sección del Periódico Oficial del Estado de Michoacán, el miércoles 30 de septiembre de 2015.

Código Familiar para el Estado Libre y Soberano de Morelos, publicado en el Periódico Oficial el 2006/09/06.

Código Civil para el Estado de Nayarit, publicado en la Segunda Sección del Periódico Oficial del Estado de Nayarit, el sábado 22 de agosto de 1981.

Código Civil para el Estado de Nuevo León, publicado en el Periódico Oficial, el sábado 6 de julio de 1935 .

Código Civil para el Estado de Querétaro, publicado en el Periódico Oficial, el 20 de octubre de 2009.

Código Civil Para el Estado de Tamaulipas, publicado mediante Decreto No. 441, del 10 de diciembre de 1986.

Código Civil para el Estado de Veracruz de Ignacio de la Llave, publicado en el suplemento especial de la Gaceta Oficial. Órgano del Gobierno del Estado de Veracruz-Llave, el 15 de septiembre de 1932.

Código Familiar del Estado de Yucatán, publicado el 16 de octubre de 2007.

Semanario Judicial de la Federación y su Gaceta, t. XXIII, Febrero de 2006, Tesis: P. /J. 11/2006, p. 1527.

\section{EN LÍNEA}

BÁEZ SILVA, Carlos, "La omisión legislativa y su inconstitucionalidad en México", En busca de las normas ausentes, 2a. ed., Ensayos sobre inconstitucionalidad por omisión, en Miguel Carbonell (Coord.), México, UNAM, Instituto de Investigaciones Jurídicas, disponible en: <https://archivos. juridicas.unam.mx/www/bjv/libros/5/2455/10.pdf>. 
BOLAÑOS, Iñaki, "El Síndrome de Alienación Parental. Descripción y Abordajes Psico-Legales”, Psicopatología Clínica, Legal y Forense, [en línea], Madrid, Vol. 2, No. 3, 2002, p. 28, Disponible en: <http://eoepsabi.educa. aragon.es/descargas/G_Recursos_orientacion/g_4_orientacion_familiar/ g_4.3.separacion/2.5.SAP_abordaje_psico-legal.pdf>.

Comisión de Derechos Humanos del Distrito Federal, [en línea], disponible en: <https://cdhdf.org.mx/2017/08/la-cdhdf-reconoce-la-proteccion-de-los-derechos-humanos-a-traves-de-la-derogacion-de-la-mal-denominada-figura-de-alienacion-parental-del-codigo-civil-de-la-ciudad-de-mexico>.

CRÓNICAS DEL PLENO Y DE LAS SALAS, [en línea], disponible en: <https://www.scjn.gob.mx/sites/default/files/sinopsis_asuntos_destacados/ documento/2017-12/TP-241017-NLPH-0011.pdf>.

DOUGLAS DARNALL, Ph. D, "Tres tipos de PAS", APADESHI Asociación de padres Alejados de sus Hijos, [en línea], disponible en: <http://sindromedealienacionparental.apadeshi.com/tres_tipos_de_pas__douglas_darn.htm>.

Gaceta Oficial de la Ciudad de México, publicada el 4 de agosto de 2017, [en línea], disponible en: <http://data.consejeria.cdmx.gob.mx/portal_old/ uploads/gacetas/37de4769c776616bfdb182dc53f08ba7.pdf $>$.

OROPEZA ORTIZ, José Luis, "Sindrome de Alienación Parental Actores Protagonistas", Revista Internacional de Psicología, Instituto de la Familia Guatemala, [en línea], Vol. 8, ISSN 1818-1023, N² , julio, 2007, pp. 18, disponible en: <http://www.revistapsicologia.org/index.php/revista/article/ download $/ 47 / 44>$.

Proposición con punto de acuerdo, por el que se exhorta respetuosamente a diversas autoridades a revisar la figura del síndrome de alienación parental preponderando el interés superior de la niñez. [en línea], disponible en: <http:/www.senado.gob.mx/sgsp/gaceta/63/2/2017-08-16-1/assets/ documentos/PA_PRD_Alienacion_Parental.pdf $>$.

RANGEL HERNÁNDEZ, Laura M., "El control de las omisiones legislativas en México. Una invitación a la reflexión”, La ciencia del derecho procesal cons- 
titucional. Estudios en homenaje a Héctor Fix-Zamudio en sus cincuenta años como investigador del derecho, t. VIII, Procesos constitucionales orgánicos, México, UNAM, Instituto de Investigaciones Jurídicas, disponible en: <https://archivos.juridicas.unam.mx/www/bjv/libros/6/2553/26. pdf>.

STANLEY,Jablonski, Síndrome: un concepto en evolución. ACIMED [en línea]. 1995, vol.3, n.1, pp. 30-38. ISSN 1024-9435, disponible en: <http://scielo. sld.cu/scielo.php? script=sci_arttext\&pid=S1024-94351995000100006〉. 